\title{
"They Told Me To Leave": How Health Care Providers Address Intimate Partner Violence
}

\author{
Diane S. Morse, MD, Ross Lafleur, BA, Colleen T. Fogarty, MD, MSc, Mona Mittal, \\ $P h D$, and Catherine Cerulli, JD, $P h D$
}

Background: Intimate partner violence (IPV) victims frequently seek medical treatment, though rarely for IPV. Recommendations for health care providers (HCPs) include IPV screening, counseling, and safety referral. The objective of this study was to report women's experiences discussing IPV with HCPs.

Methods: This study used structured interviews with women reporting IPV discussions with their HCP; descriptive analyses and bivariate and multivariate analyses were performed, and association with patient demographics and substance abuse was reviewed. We included women from family court; a community-based, inner-city primary care practice; and a tertiary care-based, outpatient psychiatric practice.

Results: A total of 142 women participated: 44 from family court (31\%), 62 from a primary care practice $(43.7 \%)$, and 36 from a psychiatric practice $(25.4 \%)$. Fifty-one percent $(n=72)$ of patients reported that HCPs knew of their IPV. Of those, $85 \%(n=61)$ told a primary care provider. Regarding IPV attitudes, 85\% $(n=61)$ found their HCP open, and $74 \%(n=53)$ found their HCP knowledgeable. Regarding approaches, $71 \%(\mathrm{n}=51)$ believed their HCP advocated leaving the relationship. Whereas $31 \%(n=22)$ received safety information, only $8 \%(n=6)$ received safety information and perceived their HCP as not advocating leaving the abusive relationship.

Conclusions: Half of participants disclosed IPV to their HCPs, and most perceived their provider advocated them leaving the relationship. Only $31 \%$ reported that HCPs provided safety planning despite increased risks associated with leaving. We suggest HCPs improve safety planning with patients who disclose IPV. (J Am Board Fam Med 2012;25:333-342.)

Keywords: Doctor-Patient Relations, Domestic Violence, Women's Health

Intimate partner violence (IPV) is a major public health concern affecting approximately $24 \%$ of US women at some point in their lifetimes. ${ }^{1}$ Experiencing IPV is associated with negative mental and physical health outcomes and increased use of health care services. ${ }^{2-4}$ Ample research demon-

This article was externally peer reviewed.

Submitted 9 June 2011; revised 18 December 2011; accepted 21 December 2011.

From the Department of Psychiatry (DSM, RL, CC), the Department of Medicine (DSM), the Department of Family Medicine (CTF), and the Department of Community and Preventative Medicine (MM), University of Rochester School of Medicine, Rochester, NY.

Funding: Funding provided by National Institute of Mental Health grants T32 MH18911, K01MH75965-01, and $\mathrm{K} 01 \mathrm{MH} 080660-01 \mathrm{~A} 2$, as well as the McGowan Foundation.

Conflict of interest: none declared.

Corresponding author: Diane S. Morse, MD, 300 Crittenden Blvd., Department of Psychiatry, University of Rochester School of Medicine, Rochester, NY 14642 (E-mail: Diane_Morse@urmc.rochester.edu). strates significant financial costs to both the patient and the health care system. ${ }^{5}$ Primary care estimates of IPV prevalence range from $4.9 \%$ to $29 \%$ and up to nearly $50 \%$ in inner-city practices. ${ }^{4-13}$ Approximately one third of women injured during their most recent physical assault received medical treatment, providing an opportunity for health care providers (HCPs) such as physicians, nurses, physician assistants, and nurse practitioners to intervene. ${ }^{14}$ However, most outpatient visits by women experiencing IPV are for non-injury-related complaints, and most affected women do not spontaneously disclose their IPV, thus highlighting the need for comprehensive measures to identify IPV. ${ }^{15,16}$ IPV has been found to be underdocumented in clinical settings. ${ }^{16}$ Interviews with $\mathrm{HCPs}^{17}$ and transcripts of patient-physician encounters ${ }^{18}$ have demonstrated that HCPs often have difficulty asking about IPV as well as addressing IPV when it is 
disclosed. These findings have generated numerous training tools and interventions to help HCPs better address IPV, but no study has demonstrated sustained improvements in addressing IPV in clinical practice. ${ }^{19-21}$ Sims et al ${ }^{15}$ reported no increase in questioning about IPV after an educational intervention for trauma residents, suggesting that education alone may not increase IPV detection without profession-wide guidelines. In addition, documenting IPV by using standard diagnostic codes may warrant caution given concerns for safety and confidentiality. ${ }^{22}$ In response to the accumulated evidence, the Institute of Medicine (IOM) of the National Academies and the Department of Health and Human Services have recommended culturally sensitive and supportive screening as well as counseling for current or past IPV for all women and adolescent girls. $^{23}$

Nearly 20 years of research about IPV identification and HCP communication may have affected community practice standards. Recommendations have been based on both preferences and outcomes reported by IPV survivors and include referral to IPV specialists, safety planning, and providing nonjudgmental support regardless of the woman's decision to stay or leave the relationship. ${ }^{24-29}$ However, there is little knowledge outside of controlled educational interventions about the extent to which current medical practitioners follow expert recommendations, such as those issued by the IOM.

There is a paucity of literature about women's comfort with discussing experiences of IPV with health care providers as well as the degree of confidence women have in their providers' advice. McCauley et $\mathrm{al}^{30}$ found that women frequently cited fear of HCP response as a barrier to disclosure. A qualitative study of IPV survivors identified 5 dimensions of provider behaviors that facilitated patient trust: open communication, professional competency, accessible practice style, caring, and emotional equality. ${ }^{31}$ Another qualitative study of IPV survivors in emergency, primary care, and obstetric/gynecologic settings concluded that patient satisfaction was related to provider acknowledgment of the abuse, respect, and relevant referrals, ${ }^{32}$ and a quantitative experimental evaluation of a system change intervention to improve emergency department responses to IPV showed that those who were screened for IPV in an emergency department had higher patient satisfaction than those who were not. ${ }^{33}$ Studies of women's preferences regarding mandatory reporting indicate that abused women prefer to be given options about what actions to take, rather than being advised directly to leave an abusive partner. ${ }^{34,35}$ Although studies have addressed patient preferences, the degree of patient comfort with and confidence in HCPs' IPV knowledge and advice after such clinical discussions have not been reported. HCPs may not be knowledgeable about the risks of leaving the abusive relationship without a safety plan in place ${ }^{36}$ or the complexity of women's decisions about leaving or staying and therefore may simply recommend leaving the relationship or respond judgmentally to a woman who expresses ambivalence about leaving. The purpose of this study was to understand women's perspectives about their experience with IPV disclosure in health care settings and to compare this with current expert guidelines for screening and intervention by HCPs.

\section{Methods}

In this study, we present the first analysis of this subsample from a larger project studying IPV-related health care and patient attitudes. Methods for this study are based on community-based participatory research strategies. ${ }^{37}$ The research team conducted preliminary discussions with women from a local battered women's shelter to obtain input about study recruitment and methodology. These women also participated in mock structured research interviews; the research team incorporated their feedback into the study protocol and structured interview script. ${ }^{38}$

\section{Participants and Settings}

Between February, 2007, and July, 2008, research assistants recruited participants from a family court, a primary care practice, and a tertiary carebased outpatient psychiatric practice for a health care research project. These sites were chosen to draw a sample of women with a range of experiences with health care. We specifically in the courts women who might not have an identified medical home. Inclusion criteria for the study were age older than 18 years, ability to consent, and selfreported lifetime history of IPV. Participants were asked to identify one abusive relationship, either past or present, and anchor all questions being asked to that relationship. 


\section{Procedures}

At both health care sites (inner city primary care practice and hospital-based psychiatric practice), primary providers were trained to screen all patients for a lifetime history of IPV using an identification tool for domestic violence that was embedded into a preexisting practice questionnaire. Those who screened positive were invited to meet with a research assistant conducting a study regarding relationships. At the primary care practice, a poster in the patient waiting area also advertised the study. At family court, recruiters approached potential participants in 2 locations: the secure area designated for petitioners of orders of protection and from a family court reception area.

At each site, trained recruiters arranged for a private, onsite interview or follow-up appointment with interested participants. Participants received a \$25 cash incentive after the interview was completed, a small resource card with the names and numbers of appropriate agencies to provide the patient with information about abusive relationships, and a hotline number to speak with someone as needed. Those who declined participation at any stage in the process were offered only the small resource card.

\section{Measures and Analyses}

The survey included questions about demographic characteristics and patient interactions and discussions with HCPs about IPV.

\section{Demographic Characteristics}

Participants reported their age (recoded as 18 to 35 years, 36 to 45 years, or 46 to 65 years); education (recoded as high school graduate or less, or some college or more); individual income (recoded as less than $\$ 20,000$ or $\$ 20,000$ or more); ethnicity (recoded as white or nonwhite); and substance use (answered yes or no to having a problem with drugs or alcohol). Substance use was included because of its associated risk with IPV. ${ }^{39}$

\section{HCP-Patient Interactions Regarding IPV}

On the basis of the input from shelter participants noted earlier, the team developed 12 questions to assess HCP- and patient-driven communication regarding patients' experiences with IPV. Participants were asked if their HCPs asked them about abuse in their intimate relationships, excluding the screen done just before study recruitment. They also were asked to answer questions about their HCPs' openness, ability to help, and influence on

Table 1. Interview Responses Regarding Healthcare Provider Communication

\begin{tabular}{|c|c|c|c|}
\hline Question & Yes & No & No Answer \\
\hline $\begin{array}{l}\text { Did your health care provider know that physical violence or emotional } \\
\text { abuse was occurring in your relationship? }\end{array}$ & $72(51)$ & $70(49)$ & $0(0)$ \\
\hline $\begin{array}{l}\text { If your health care provider had asked you about the physical violence } \\
\text { and/or the emotional abuse in your relationship, would you have told } \\
\text { him/her?* }\end{array}$ & $46(66)$ & $21(30)$ & $3(4)$ \\
\hline $\begin{array}{l}\text { Do you think that your health care provider helped you to make your } \\
\text { decision about whether to stay or to try to leave your violent/abusive } \\
\text { relationship? }\end{array}$ & $28(39)$ & $39(54)$ & $5(7)$ \\
\hline Was your health care provider open to hearing about the violence/abuse? & $61(85)$ & $5(7)$ & $6(8)$ \\
\hline Were you comfortable approaching him or her? & $47(65)$ & $20(28)$ & $5(7)$ \\
\hline $\begin{array}{l}\text { Do you think your health care provider is knowledgeable about what } \\
\text { goes on in violent/abusive relationships? }\end{array}$ & $53(74)$ & $11(15)$ & $8(11)$ \\
\hline Which health care providers knew? & - & - & - \\
\hline $\begin{array}{l}\text { How did you feel about your health care provider knowing that physical } \\
\text { violence and/or emotional abuse was occurring in your relationship? }\end{array}$ & - & - & - \\
\hline What was it that he/she said that was helpful to you? & - & - & - \\
\hline What was it that he/she said that was not helpful to you? & - & - & - \\
\hline $\begin{array}{l}\text { Do or did you think your health care provider wants/wanted you to stay } \\
\text { or to leave your violent/abusive relationship? }\end{array}$ & $\begin{array}{l}\text { Leave } \\
51(71)\end{array}$ & $\begin{array}{l}\text { Stay } \\
5(7)\end{array}$ & $\begin{array}{c}\text { Neutral } \\
16(22)\end{array}$ \\
\hline How do you know this? & - & - & - \\
\hline
\end{tabular}

Values provided as $\mathrm{n}(\%)$.

*Asked only of participants who answered No to question $1(\mathrm{n}=70)$. 
their decision to stay or leave the abusive relationship (see Table 1).

\section{Data Analysis}

We conducted a mixed-method analysis ${ }^{40}$ of the scribed, semistructured interviews, which we informed with selective qualitative quotes from women who found their disclosure to their HCP to be either helpful or unhelpful. $\chi^{2}$ tests were conducted to determine the associations between participant demographic and background variables and recruitment site (see Table 2).

Descriptive analyses of the qualitative data were performed. For the portion of the structured interview questions that were open-ended, 2 individuals (one co-author [RL] and one research assistant [JB]) coded the narratives to help determine the nature of the HCP-patient communication regarding IPV. The coding was done separately, and any disagreements were resolved by discussion until consensus occurred. Regarding whether the HCP directly advised the patient to stay or leave, we looked to the "How do you know?" (that your HCP wished for you to stay or leave) question (Table 1). Regarding safety advice or referral and how the HCP was helpful or unhelpful, we looked for references to that physician behavior in all the openended questions (Table 1). We selected some participants' narrative statements that were illustrative of the major themes regarding helpful or unhelpful
HCP behaviors or statements from the structured interviews to further inform this analysis.

We quantified the various HCPs with whom patients discussed IPV, as shown in Figure 1. To assess whether demographic characteristics were associated with HCPs asking about IPV or not, we performed multivariate logistic regression with the HCPs asking about IPV as the dependent variable and age, race, substance abuse history, and employment as independent variables for all 142 participants. Lastly, we performed $\chi^{2}$ bivariate analysis with 72 participants who reported discussing IPV with an HCP. We analyzed variables relating to these participants' views of their HCPs' attitudes, perceptions, and knowledge about the care of women in abusive relationships.

\section{Results}

Data were available from 142 of the original 150 women who took part in the health care study (we excluded 8 participants because of missing demographic data). Sixty-one percent $(n=87)$ of the women were nonwhite. Participants had relatively low educational attainment, with $68 \%(\mathrm{n}=97)$ having earned a high school diploma or less, and were low income, with $88 \%(\mathrm{n}=124)$ reporting an annual individual income less than $\$ 20,000$. Participation criteria required an age range from 18 to 65 years, with $41 \%(n=59)$ aged 18 to 35 years, $32 \%$

Table 2. Demographics of Sample, Represented by Site of Participation

\begin{tabular}{|c|c|c|c|c|c|c|}
\hline Demographic & $\begin{array}{l}\text { Patients in } \\
\text { Strata (n) }\end{array}$ & $\begin{array}{l}\text { Respondents in } \\
\text { Category (\%) }\end{array}$ & $\begin{array}{c}\text { Family } \\
\text { Court (\%) }\end{array}$ & $\begin{array}{l}\text { Community Health } \\
\text { Center }(\%)\end{array}$ & $\begin{array}{l}\text { Behavioral } \\
\text { Health (\%) }\end{array}$ & $P$ \\
\hline Overall sample & 142 & & 31 & 43.7 & 25.4 & \\
\hline \multicolumn{7}{|l|}{ Race } \\
\hline White & 55 & 38.7 & 29.5 & 33.9 & 58.3 & .018 \\
\hline Nonwhite & 87 & 61.3 & 70.5 & 66.1 & 41.7 & \\
\hline \multicolumn{7}{|l|}{ Age (years) } \\
\hline $18-35$ & 59 & 41.5 & 65.9 & 29.0 & 33.3 & .001 \\
\hline $36-45$ & 45 & 31.7 & 22.7 & 41.9 & 25.0 & \\
\hline $46-65$ & 38 & 26.8 & 11.4 & 29.0 & 41.7 & \\
\hline \multicolumn{7}{|l|}{ Educational level } \\
\hline Some college or more & 45 & 31.7 & 17 & 12 & 16 & .018 \\
\hline High school grad or less & 97 & 63.3 & 27 & 50 & 20 & \\
\hline \multicolumn{7}{|l|}{ Household Income $(\$)^{*}$} \\
\hline$\leq 20,000$ & 124 & 87.9 & 37 & 57 & 30 & .215 \\
\hline$\geq 20,000$ & 17 & 12.1 & 7 & 4 & 6 & \\
\hline Alcohol a problem (yes) & 21 & 14.8 & 2.3 & 24.2 & 13.9 & .007 \\
\hline Drugs a problem (yes) & 33 & 23.2 & 25.0 & 25.8 & 16.7 & .555 \\
\hline
\end{tabular}


Figure 1. Interview response percentages to question, "Which health care providers knew [about your relationship violence]?"

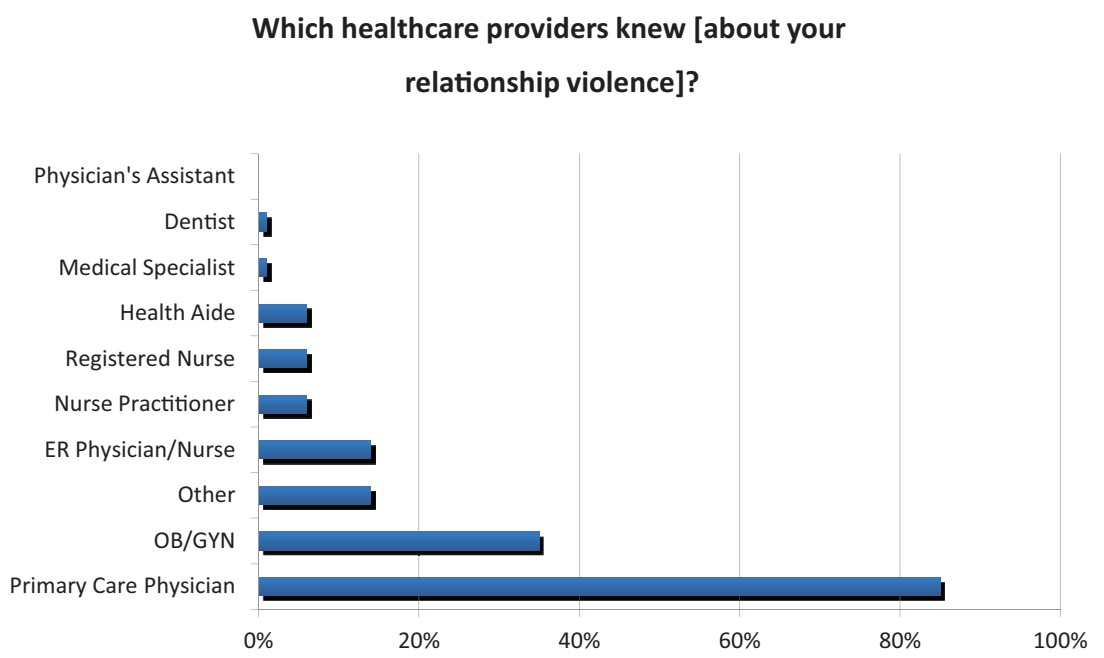

$(\mathrm{n}=45)$ aged 36 to 45 years, and $27 \%(\mathrm{n}=38)$ aged 46 to 65 years.

The demographics of the sample, divided by recruitment site, are displayed in Table 2. The demographics of our participants differed by site for race, age, education, and alcohol abuse. The family court $(70.5 \% ; \mathrm{n}=31)$ and primary care practice $(66.1 \%$; $\mathrm{n}=41)$ sites had more minority women compared with the psychiatric practice $(41.7 \% ; n=15)$. Family court also had a greater number of younger women $(65.9 \% ; \mathrm{n}=29)$. Twenty-four percent of respondents at the primary care practice noted an alcohol problem, in contrast with only $13.9 \%$ and $2.3 \%$ at the psychiatric practice and family court sites, respectively. Differences in reported drug use between sites were not significant. Notwithstanding these differences in race, age, and alcohol abuse, we combined the samples for our subsequent analyses because they represent predominantly low-income women with histories of relationship violence.

Of the 142 female participants, $51 \%(\mathrm{n}=72)$ reported that their HCPs-including medical doctors, nurses, nurse practitioners, and physician assistants-knew of the abuse in their relationships (see Table 1). Of those participants, 65\% $(\mathrm{n}=47)$ reported that they had been asked about IPV by a HCP, which indicates that $65 \%$ of these HCPs are following the recommended guidelines. However, in a different question, only $31 \%(n=22)$ reported having volunteered information about IPV to an HCP. Eighty-five percent of the participants whose HCP knew of their abuse $(n=61)$ reported having told at least one primary care provider, including 25 who said they reported to their obstetrician/ gynecologist. Of the $49 \%(n=70)$ who reported that their HCPs did not know about the abuse, $63 \%(\mathrm{n}=44)$ indicated they would have disclosed the information if their HCP had asked.

Logistic regression revealed that race, employment, and self-reported drug use were not associated with an HCP asking about IPV. However, women aged 36 to 45 years were almost 4 times as likely to say they had been asked (odds ratio, 3.99; $95 \%$ confidence interval, 1.53-10.44) compared with the reference group (women aged $\leq 36$ years).

Of the 72 women who reported that their HCP knew about the abuse, $85 \%(\mathrm{n}=61)$ reported their HCP was open to talking about IPV, $65 \%(n=47)$ felt comfortable approaching their HCP about it, and $74 \%(\mathrm{n}=53)$ felt their HCP was knowledgeable about the topic.

Among the 72 participants whose HCPs knew of the abuse, $71 \%(n=51)$ reported they felt their HCPs wanted them to leave the abusive relationships, and half of those $(\mathrm{n}=27)$, or $37.5 \%$ of the total, stated that their HCP specifically advised them to leave their abusive partners (see Table 3). Twenty-five percent $(\mathrm{n}=18)$ of the abused women reported their HCP advised them to leave the abusive partner but the women did not indicate they were given any safety advice. Few participants $(31 \% ; \mathrm{n}=22)$ reported safety assistance such as referral to community agencies. Only 6 women (8\%) stated that HCPs 
Table 3. Responses to the Question, "Do or Did You Think Your Health Care Provider Wants/Wanted You to Stay or to Leave Your Violent/Abusive Relationship?"

\begin{tabular}{|c|c|c|c|c|c|c|}
\hline & & $\begin{array}{l}\text { Leav } \\
n=\end{array}$ & & & & \\
\hline & Yes & No & Total & $(\mathrm{n}=5)$ & $(\mathrm{n}=16)$ & $(\mathrm{n}=72)$ \\
\hline Advised to leave & 27 & 24 & 51 & & & \\
\hline Received safety advice & 9 & 5 & 14 & 2 & 6 & 22 \\
\hline Did not receive safety advice & 18 & 19 & 37 & 3 & 10 & 50 \\
\hline Advice was helpful & 10 & 10 & 20 & 2 & 6 & 28 \\
\hline Advice was not helpful & 15 & 11 & 26 & 3 & 10 & 39 \\
\hline
\end{tabular}

offered safety advice and left the decision about leaving or staying in the abusive relationships to them. Considered by site among the same 72 participants who spoke with their HCP about abuse, $43 \%(n=9)$ recruited at the psychiatric practice reported receiving safety advice, compared with $31 \%(n=10)$ at the primary care practice and $16 \%(n=3)$ recruited at the family court.

The following quotes are from participants who described the HCP as helpful:

"[My doctor] was a friend and the only one I could trust..."

"[My doctor was $]$ compassionate, supportive. She took her time with me and spent about 2 bours when I broke down."

"I felt like it helped me because [the doctor] was supporting my decision to get help..."

"He will kill you-get out..." [HCP statement to participant]

The following quotes are from participants who described the HCP as unbelpful:

"I felt scared that [the doctor] would report me to the police, welfare..."

"Persons in emergency brought up the situation when my husband was still there...then they asked him to leave and I was scared."

"'All those times that you kept going back, I told you not to go back, now you are on your own.' [HCP statement to participant] I changed doctors after that."

"[I felt] embarrassed and unprotected. I felt like [my doctor] defended my husband."

"I was in such denial that I didn't want to hear any of her advice and opinions; closed ears..."

"I want to get pregnant. My OB/GYN [won't prescribe] my meds, so I won't get pregnant. If I leave him she will give them to me again. I have an illness that keeps me from getting pregnant."

\section{Discussion}

In this study of 142 low-income women who have experienced IPV, half of the participants reported disclosing abuse to an HCP. Of those who disclosed IPV to an HCP, $65 \%$ did so in response to being asked; only $31 \%$ volunteered their IPV status. Among those who did not disclose to an HCP, $63 \%$ stated that they would have disclosed if they had been asked. Eighty-five percent of the women who disclosed IPV told a primary care provider. Among the women that disclosed IPV to an HCP, $71 \%$ felt that their provider wanted them to leave the relationship, with $37.5 \%$ reporting being specifically directed to leave. Among the women who disclosed IPV to an HCP, 69\% were not provided safety advice. Finally, among the women who disclosed IPV to an HCP, $65 \%$ to $85 \%$ felt comfortable and believed their HCP to be open or knowledgeable regarding IPV. In this study, women aged 36 to 45 years are 4 times more likely to be screened for IPV.

Most of our participants who told an HCP about IPV reported having disclosed their abuse to a primary care provider. This finding demonstrates the prominent role such providers play for these patients and supports current recommendations for primary care providers to screen for and address IPV. Importantly, women seeking orders of protection sought care at the emergency department at twice the rate that they utilized primary health care, and $40 \%$ reported delayed medical care in the past year. ${ }^{38}$ Hence, HCPs may see a patient only once, further reinforcing asking all patients about IPV, even at the first visit.

Another important finding in our study is that only half of our participants had disclosed IPV to a HCP; almost two thirds of those disclosed IPV only when they were asked, and most of those who 
did not disclose IPV reported that they would have disclosed it if they had been asked. These findings support the practice of routine inquiry of IPV in all patients, as has recently been recommended by an IOM report, ${ }^{23}$ a recommendation accepted by the secretary of the DHHS. Women who have disclosed their IPV experience to an HCP have been found to be more likely to report receiving an IPV intervention, which is associated with leaving the abusive relationship and improved health outcomes. $^{41,42}$ Not inquiring of all patients ensures that IPV will be underdetected and therefore undertreated. To fulfill the DHHS directives, HCPs will benefit from using evidence-based guidelines to respond to women who disclose IPV on routine inquiry.

Among our participants, 69\% reported that they had not received safety advice regarding IPV, whereas $71 \%$ reported feeling that their HCP wanted them to leave the abusive relationship. If providers feel helpless to address the needs of women experiencing IPV, they may focus on counseling the woman to leave the abusive relationship without adequately providing information about other strategies and, if the woman wants to leave, ensuring safety procedures are in place. Risk of femicide is increased significantly during the year after an abused partner leaves the abuser, ${ }^{36}$ yet only $50 \%$ of survivors of attempted femicide reported being aware of their extreme risk, hence increasing susceptibility to possibly unsafe suggestions or a lack of adequate safety planning. ${ }^{43}$ Furthermore, some abused women reported that fearing providers will require them to leave an abusive relationship to receive help was a barrier to seeking such help, supporting the importance of our results. ${ }^{44}$

A positive finding in this study is the degree of comfort with and confidence in their HCPs, most of whom were primary care providers, that abused women reported and the extent to which the women looked to the HCPs for help in managing this complex situation. However, there is discordance between this confidence and the finding that HCPs rarely provided safety planning and a nonjudgmental approach to the question of staying or leaving the abusive relationship. In addition, supporting patients' autonomy to make their own choices is associated with other positive outcomes such as improvements in satisfaction, well-being, and change associated with intrinsic rather than extrinsic motivation. ${ }^{45,46}$
Our finding that participants perceived their HCP to be advocating leaving the abusive relationship raises the question of whether someone who becomes aware of a dangerous (physically, emotionally, or both) situation would not reasonably want the person in danger to leave it. It is also possible that those participants who were not directly advised to leave may have assumed their provider wanted them to do so because it is one reasonable response to an abusive relationship. The fundamental question is whether someone can be supportive of a patient making her own decision and still want her to change her situation. Research on motivation regarding substance abuse and adherence to medical recommendations helps to address these questions. Empathy, information, and support can be provided to increase patient autonomy and perceived competence, consequently improving health outcomes. ${ }^{47-49}$ Qualitative research among the IPV survivor population supports the notion that respectful information-sharing and support by HCPs will help break the cycle of control, degradation, and physical violence that constitutes IPV. ${ }^{28-31}$

In July 2011 the IOM recommended universal IPV screening, noting the prevalence of IPV and the need to address current and future health risks. ${ }^{23}$ Nevertheless, there has been a lack of consensus regarding the utility of screening women for $\mathrm{IPV} .{ }^{50} \mathrm{It}$ is possible that one reason for the lack of clear efficacy of some screening interventions relates to the difficulty HCPs have with the complex and numerous tasks that have been suggested when the patient screens positively, such as assessing mechanisms of injury and child safety. ${ }^{51}$ Clinical practice, policy, and research implications of this study would be to focus on establishing fewer HCP responses to a determination of ongoing IPV. In this study, participants reported that HCPs conveyed support, as has been suggested by IPV survivors, ${ }^{29}$ but did less well with safety-related suggestions. Hence, focusing educational efforts on getting HCPs to provide a referral to a trained IPV provider at a local shelter or a national toll-free hotline (1-800-799-SAFE (7233) ${ }^{52}$ may be the appropriate strategy for primary care providers with multiple important tasks. Research regarding such a strategy could be important as well.

Our results suggest that patients look to their HCP for guidance and information, giving HCPs an opportunity to respectfully educate women to 
seek safety planning and impact their ability to make positive change. The cumulative evidence suggests that, after such referrals, HCPs should support patients' choices and decrease the focus on leaving the abusive relationship until resources are present to help avoid potentially serious harm.

A strength of this study is that women were recruited from different sites. Although other articles have focused on patient responses to HCPs in primary or emergency medical settings ${ }^{18,31}$ ours broadens the population studied and adds to the literature by including participants recruited from 2 sites where biomedical care was not being obtained. Some differences by site were noted (Table 2) with regard to ethnicity and age. The family court sample was seeking an order of protection and was more likely to be younger and nonwhite, whereas the psychiatric practice clinic sample was likelier to be older and white. The primary health care population was less likely to have some college education, had a lower income, and was more likely to have an alcohol problem. These findings support our belief that we have assembled a diverse population. A larger sample may be needed to determine associated differences in IPV communication beyond the finding of women in the middle age group range being more likely to be asked about IPV by an HCP.

Our results should be considered with caution. This study is based on patient report. Other studies have utilized audiotape, videotape, or chart review to document actual HCP behaviors. This study focuses more on diverse patients' perceptions of and response to community HCPs' behaviors. Another limitation of this study is the lack of a qualitative thematic analysis of participant comments. Because such an analysis was not the purpose of this study, the depth and breadth of responses needed for such an analysis were not obtained.

Future studies could aim to test specific hypotheses regarding interactions between patient characteristics, HCP behaviors, and patient attitudes toward their HCPs. For example, do patient race, education, and income affect the likelihood that HCPs will ask about IPV? Would HCPs asking about IPV increase patient comfort and confidence and could that lead to an increase in needed health services use? If HCPs were trained to support patient autonomy regarding their decisions to stay or leave the abusive relationship, would this improve patient motivation to increase controllable safety behaviors? ${ }^{53}$ These important questions have yet to be addressed.

\section{Conclusions}

Among our diverse sample of women IPV survivors, only half felt comfortable enough to disclose IPV to an HCP. Among the half who did not disclose, $63 \%$ would have done so if they had been asked. For the half that did disclose, almost threefourths thought that their HCP wanted them to leave the relationship, and only $31 \%$ received safety information. These findings contrast with more than three fourths of the survivors believing their HCPs to be knowledgeable about abuse. Although the sample size was limited, our results have implications for provider training and for new hypotheses that can be studied in larger intervention studies.

The authors thank Susan H. Horwitz, PhD, LMFT (primary investigator of McGowan project); Michelle LaRussa-Trott, LMSW; Joan Pearson, MA, MS, LMFT; Lizette Santiago, MS, LMFT; and David Skiff, PhD, MDiv, LMSW, for their help with project design and implementation. The authors thank the interviewers: Lorena Billone, BA, MFTT, Jessica Bougie, BA, and Stacy Kolb-Tripp, MS, and their statistical consultant, Harry Reis, PhD. The authors thank Meaghan Bernstein and Jessica Band for help with data entry and management and Jacqueline Campbell, $\mathrm{PhD}, \mathrm{RN}$, for her review of the manuscript. This project would not have been possible without the support of many administrators, mentors, and most importantly, participants. Special thanks to the organizations, Safer and Delphi, that assisted this study in the design before implementation.

\section{References}

1. Breiding MJ, Black MC, Ryan GW. Prevalence and risk factors of intimate partner violence in eighteen US states/territories, 2005. Am J Prev Med 2008; 34(2):112-8.

2. Bonomi AE, Anderson M, Reid RJ, Rivara FP, Carrell D, Thompson RS. Medical and psychosocial diagnoses in women with a history of intimate partner violence. Arch Intern Med 2009;169(18):1692-7.

3. Chen PH, Rovi S, Vega M, Jacobs A, Johnson MS. Relation of domestic violence to health status among Hispanic women. J Health Care Poor Underserved 2009;20(2):569-82.

4. Thompson RS, Bonomi AE, Anderson M, et al. Intimate partner violence: prevalence, types, and chronicity in adult women. Am J Prev Med 2006; 30(6):447-57.

5. Bonomi AE, Anderson ML, Rivara FP, Thompson RS. Health care utilization and costs associated with physical and nonphysical-only intimate partner violence. Health Serv Res 2009;44(3):1052-67. 
6. Freund KM, Bak SM, Blackhall L. Identifying domestic violence in primary care practice. J Gen Intern Med 1996;11(1):44-6.

7. Gin NE, Rucker L, Frayne S, Cygan R, Hubbell FA. Prevalence of domestic violence among patients in three ambulatory care internal medicine clinics. J Gen Intern Med 1991;6(4):317-22.

8. Rath GD, Jarratt LG, Leonardson G. Rates of domestic violence against adult women by men partners. J Am Board Fam Pract 1989;2(4):227-33.

9. Bullock L, McFarlane J, Bateman LH, Miller V. The prevalence and characteristics of battered women in a primary care setting. Nurse Pract 1989;14(6):47, $50,53-6$.

10. Coker AL, Smith PH, McKeown RE, King MJ. Frequency and correlates of intimate partner violence by type: physical, sexual, and psychological battering. Am J Public Health 2000;90(4):553-9.

11. Coker AL, Flerx VC, Smith PH, Whitaker DJ, Fadden MK, Williams M. Intimate partner violence incidence and continuation in a primary care screening program. Am J Epidemiol 2007;165(7):821-7.

12. El-Bassel N, Gilbert L, Witte $S$, et al. Intimate partner violence and substance abuse among minority women receiving care from an inner-city emergency department. Womens Health Issues 2003; 13(1):16-23.

13. Porcerelli JH, Cogan R, West PP, et al. Violent victimization of women and men: physical and psychiatric symptoms. J Am Board Fam Pract 2003; 16(1):32-9.

14. Tjaden P, Thoennes N. Full report of the prevalence, incidence, and consequences of violence against women: findings from the National Violence Against Women Survey. Washington, DC: Department of Justice, National Institute of Justice; 2000. NCJ 183781.

15. Sims C, Sabra D, Bergey MR, et al. Detecting intimate partner violence: More than trauma team education is needed. J Am Coll Surg. 2011;212(5):867-872.

16. Kothari CL, Rhodes KV. Missed opportunities: emergency department visits by police-identified victims of intimate partner violence. Ann Emerg Med 2006;47(2):190-9.

17. Sugg NK, Inui T. Primary care physicians' response to domestic violence. Opening Pandora's box. JAMA. 1992;267(23):3157-60.

18. Rhodes KV, Frankel RM, Levinthal N, Prenoveau E, Bailey J, Levinson W. "You're not a victim of domestic violence, are you?" Provider patient communication about domestic violence. Ann Intern Med 2007;147(9):620-7.

19. Nicolaidis C. The voices of survivors documentary: using patient narrative to educate physicians about domestic violence. J Gen Intern Med 2002;17(2): 117-24.

20. Edwardsen EA, Morse DS, Frankel RM. Structured practice opportunities with a mnemonic affect med- ical student interviewing skills for intimate partner violence. Teach Learn Med 2006;18(1):62-8.

21. McColgan MD, Cruz M, McKee J, et al. Results of a multifaceted intimate partner violence training program for pediatric residents. Child Abuse Negl 2010;34(4):275-83.

22. Rovi S, Johnson MS. More harm than good? Diagnostic codes for child and adult abuse. Violence Vict 2003;18(5):491-502.

23. Institute of Medicine of the National Academies. Report brief. Clinical preventive services for women: closing the gaps. 19 July 2011. Available at: http:// www.iom.edu/Reports/2011/Clinical-PreventiveServices-for-Women-Closing-the-Gaps/ReportBrief.aspx. Accessed 23 November 2011.

24. Rhodes KV, Levinson W. Interventions for intimate partner violence against women: clinical applications. JAMA 2003;289(5):601-5.

25. Gerbert B, Caspers N, Bronstone A, Moe J, Abercrombie P. A qualitative analysis of how physicians with expertise in domestic violence approach the identification of victims. Ann Intern Med 1999; 131(8):578-84.

26. Du Plat-Jones J. Domestic violence: the role of health professionals. Nurs Stand 2006;21(14-16):44-8.

27. Kaur G, Herbert L. Recognizing and intervening in intimate partner violence. Cleve Clin J Med 2005; 72(5):406-9, 413-4, 417 passim.

28. Chang JC, Decker MR, Moracco KE, Martin SL, Petersen R, Frasier PY. Asking about intimate partner violence: advice from female survivors to health care providers. Patient Educ Couns 2005;59(2): 141-7.

29. Feder GS, Hutson M, Ramsay J, Taket AR. Women exposed to intimate partner violence: expectations and experiences when they encounter health care professionals: a meta-analysis of qualitative studies. Arch Intern Med 2006;166(1):22-37.

30. McCauley J, Yurk RA, Jenckes MW, Ford DE. Inside "Pandora's box": abused women's experiences with clinicians and health services. J Gen Intern Med 1998;13(8):549-55.

31. Battaglia TA, Finley E, Liebschutz JM. Survivors of intimate partner violence speak out: trust in the patient-provider relationship. J Gen Intern Med 2003; 18(8):617-23.

32. Liebschutz J, Battaglia T, Finley E, Averbuch T. Disclosing intimate partner violence to health care clinicians-what a difference the setting makes: a qualitative study. BMC Public Health 2008;8:229.

33. Campbell JC, Coben JH, McLoughlin E, et al. An evaluation of a system-change training model to improve emergency department response to battered women. Acad Emerg Med 2001;8(2):131-8.

34. Gielen AC, O'Campo PJ, Campbell JC, et al. Women's opinions about domestic violence screening and mandatory reporting. Am J Prev Med 2000;19(4): $279-85$. 
35. Sachs CJ, Koziol-McLain J, Glass N, Webster D, Campbell J. A population-based survey assessing support for mandatory domestic violence reporting by health care personnel. Women Health 2002; 35(2-3):121-33.

36. Campbell JC, Webster D, Koziol-McLain J, et al. Risk factors for femicide in abusive relationships: results from a multisite case control study. Am J Public Health 2003;93(7):1089-97.

37. Israel BA, Coombe CM, Cheezum RR, et al. Community-based participatory research: a capacitybuilding approach for policy advocacy aimed at eliminating health disparities. Am J Public Health 2010; 100(11):2094-102.

38. Cerulli C, Edwardsen EA, Duda J, Conner KR, Caine E. Protection order petitioners' health care utilization. Violence Against Women 2010;16(6): 679-90.

39. Kilpatrick DG, Acierno R, Resnick HS, Saunders BE, Best CL. A 2-year longitudinal analysis of the relationships between violent assault and substance use in women. J Consult Clin Psychol 1997;65(5): 834-47.

40. Creswell JW, Clark V. Designing and conducting mixed methods research. Thousand Oaks, CA: Sage Publications, Inc.; 2007.

41. McCloskey LA, Lichter E, Williams C, Gerber M, Wittenberg E, Ganz M. Assessing intimate partner violence in health care settings leads to women's receipt of interventions and improved health. Public Health Rep 2006;121(4):435-44.

42. Abramsky T, Watts CH, Garcia-Moreno C, et al. What factors are associated with recent intimate partner violence? Findings from the WHO multicountry study on women's health and domestic violence. BMC Public Health 2011;11:109.

43. Nicolaidis C, Curry MA, Ulrich Y, et al. Could we have known? A qualitative analysis of data from women who survived an attempted homicide by an intimate partner. J Gen Intern Med 2003;18(10): 788-94.
44. Fugate M, Landis L, Riordan K, Naureckas S, Engel B. Barriers to domestic violence help seeking: implications for intervention. Violence Against Women 2005;11(3):290-310.

45. Williams GC, McGregor HA, King D, Nelson CC, Glasgow RE. Variation in perceived competence, glycemic control, and patient satisfaction: relationship to autonomy support from physicians. Patient Educ Couns 2005;57(1):39-45.

46. Silva MN, Vieira PN, Coutinho S, et al. Using self-determination theory to promote physical activity and weight control: a randomized controlled trial in women. J Behav Med 2010;33(2):110-22.

47. Zeldman A, Ryan RM, Fiscella K. Client motivation, autonomy support and entity beliefs: their role in methadone maintenance treatment. J Soc Clin Psychol 2004;23(5):675-96.

48. Williams GC, Niemiec CP, Patrick H, Ryan RM, Deci EL. The importance of supporting autonomy and perceived competence in facilitating long-term tobacco abstinence. Ann Behav Med 2009;37(3): 315-24.

49. Williams GC, Patrick H, Niemiec CP, et al. Reducing the health risks of diabetes: How self-determination theory may help improve medication adherence and quality of life. Diabetes Educ. 2009;35(3): 484-492.

50. U.S. Preventive Services Task Force. Screening for family and intimate partner violence: recommendation statement. Ann Intern Med 2004;140(5):382-6.

51. Hamberger LK, Ambuel B, Marbella A, Donze J. Physician interaction with battered women: the women's perspective. Arch Fam Med 1998;7(6):57582.

52. National Domestic Violence Hotline [homepage on the Internet]. Available at: http://www.thehotline.org/. Accessed 12 May 2011.

53. Sheldon KM, Williams GC, Joiner T. Self-determination theory in the clinic: motivating physical and mental health. New Haven, CT: Yale University Press; 2003. 